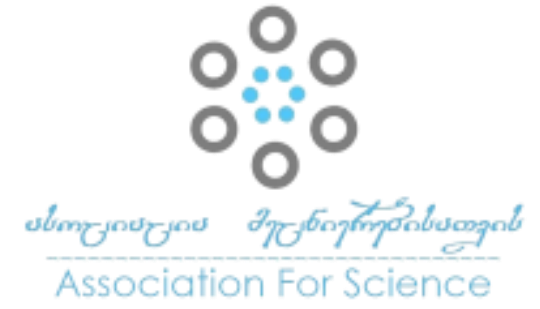

Georgian Scientists

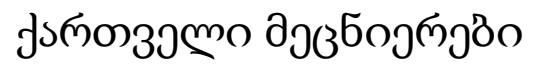

Vol. 4 Issue 1, 2022

https://doi.org/10.52340/gs.2022.04.01.02

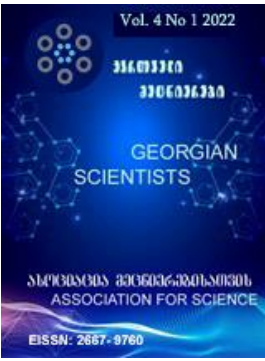

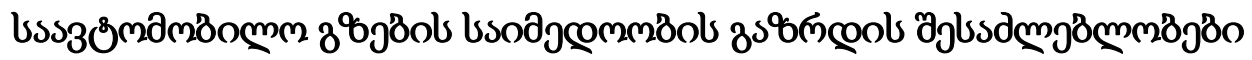

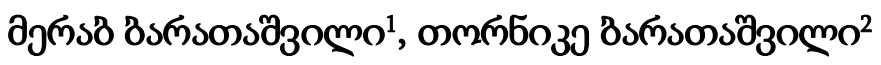

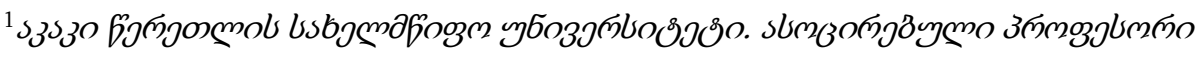

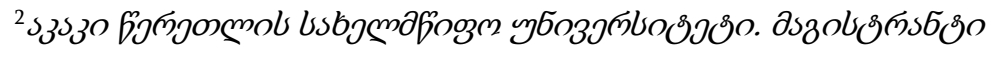

mjonyay

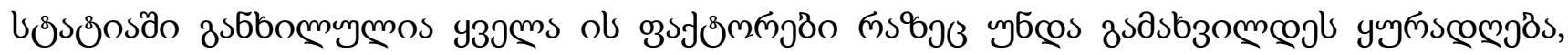

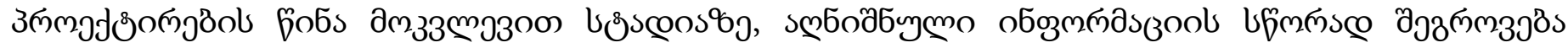

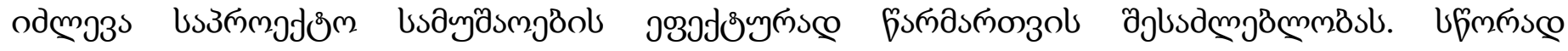

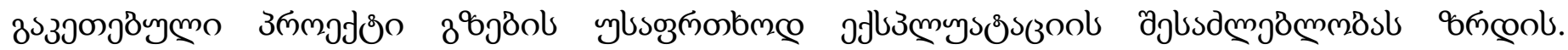

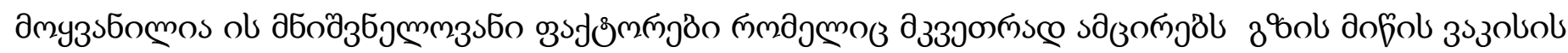

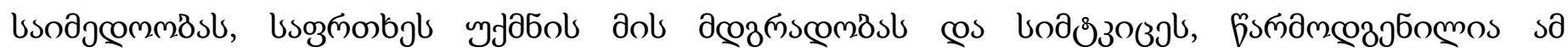

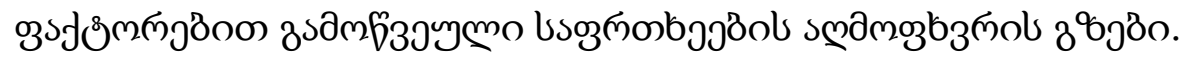

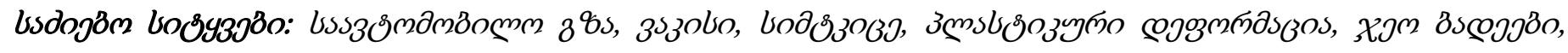

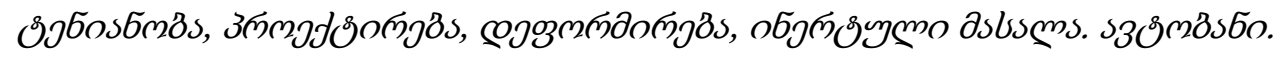




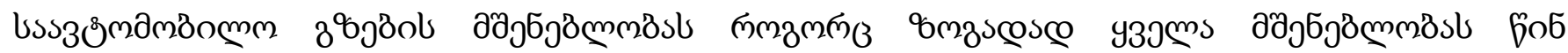

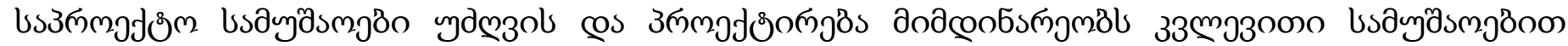

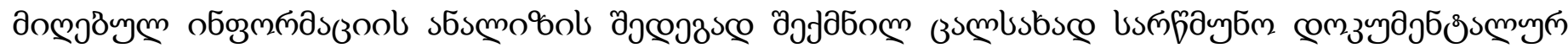

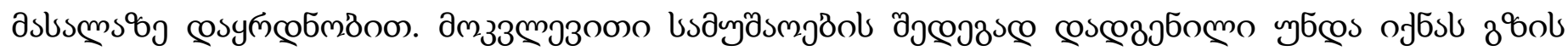

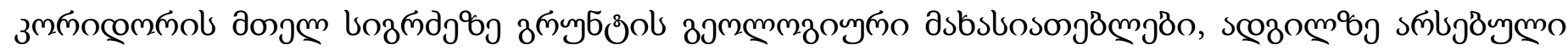

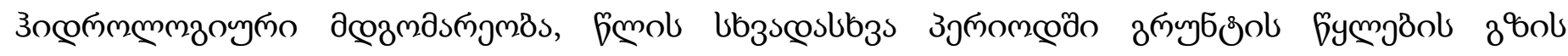

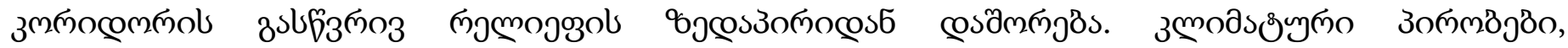

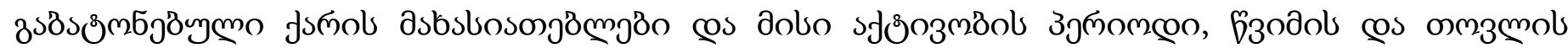

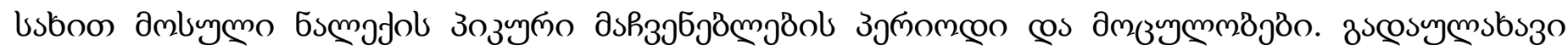

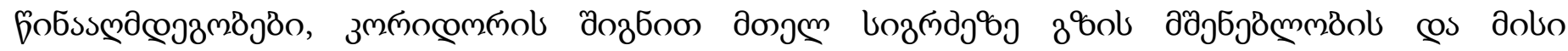

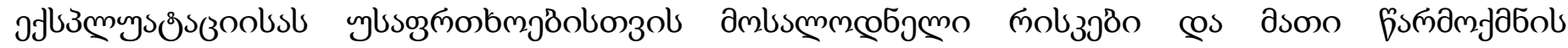

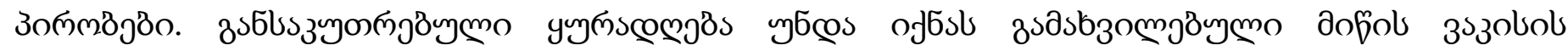

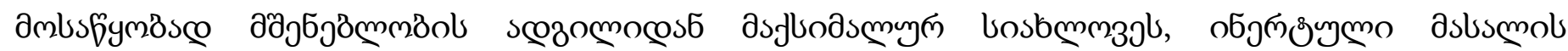

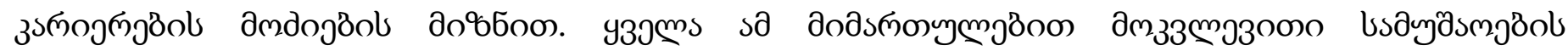

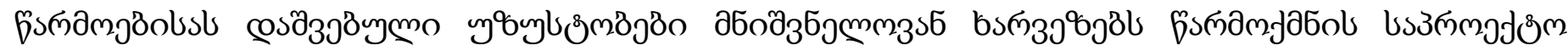

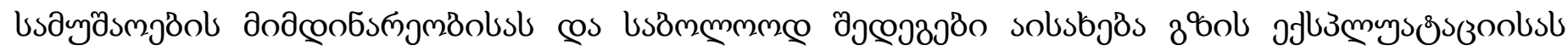

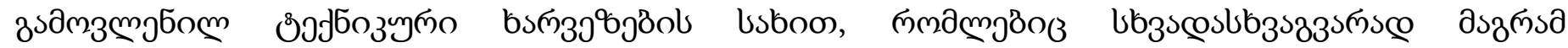

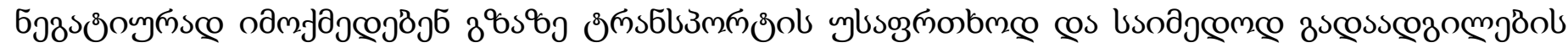

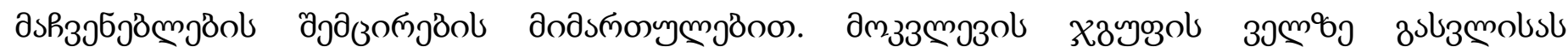

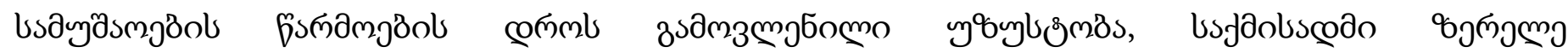

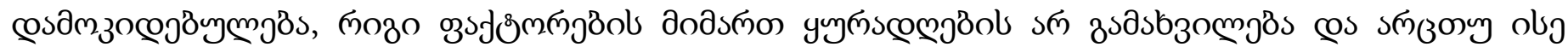

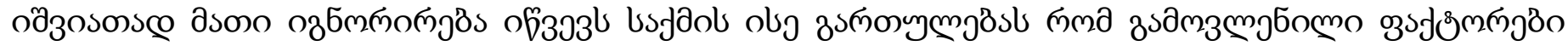

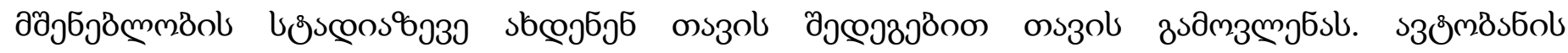

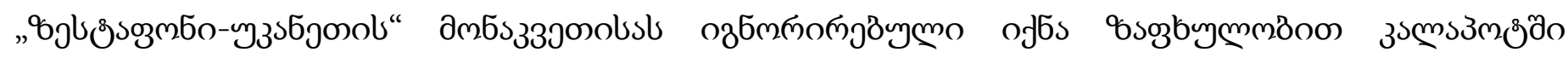

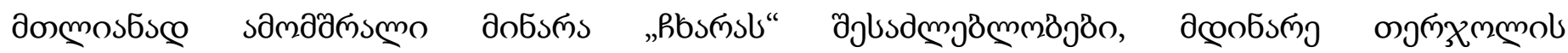
ауббозозьмпов

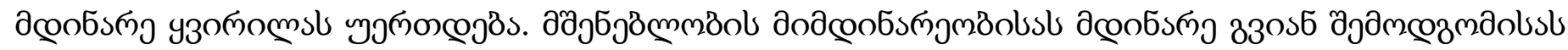

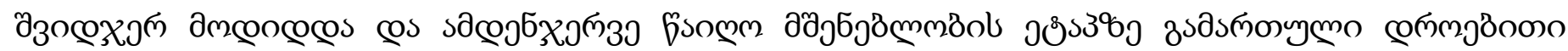

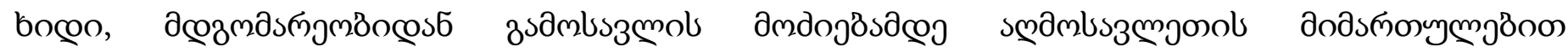

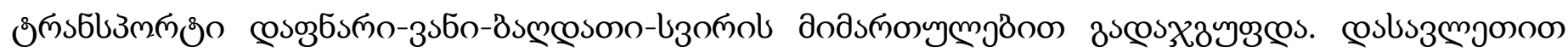




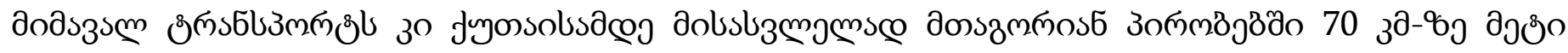

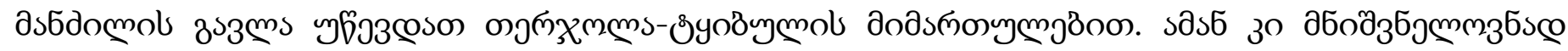

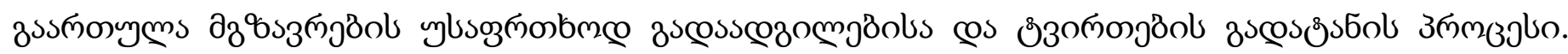

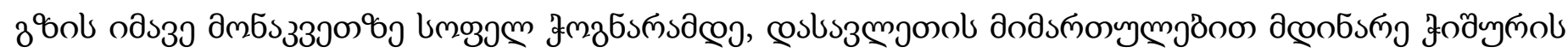

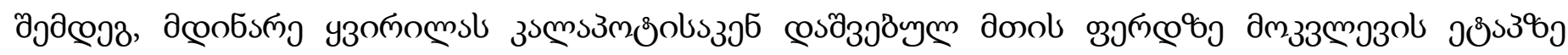

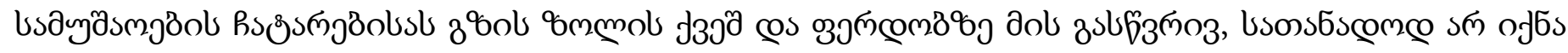

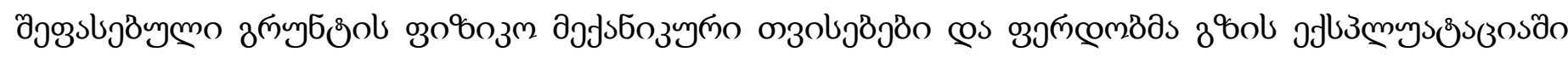

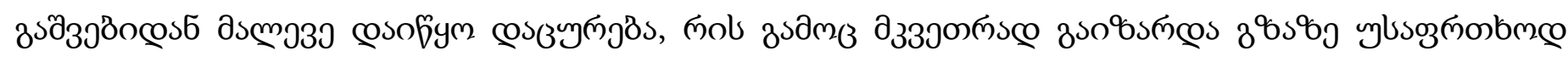

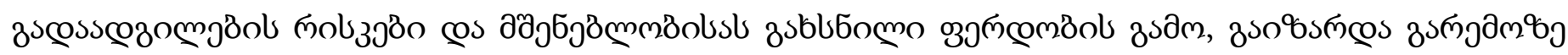

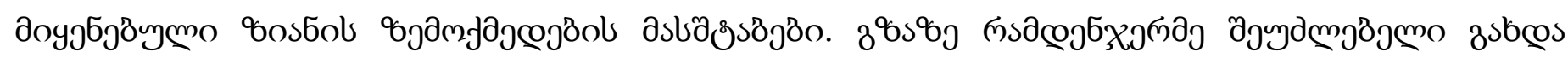

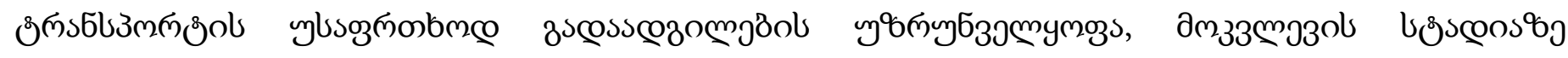

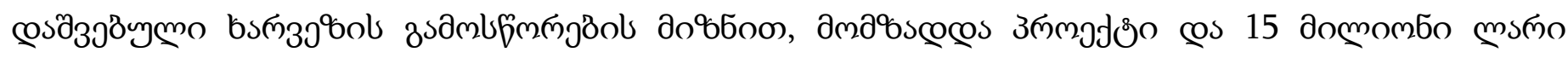

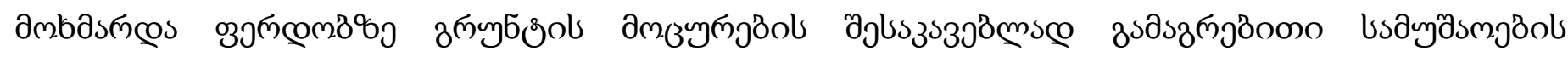

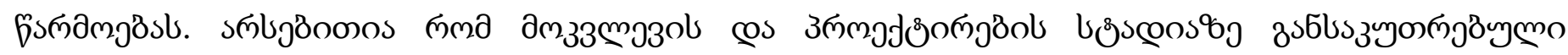

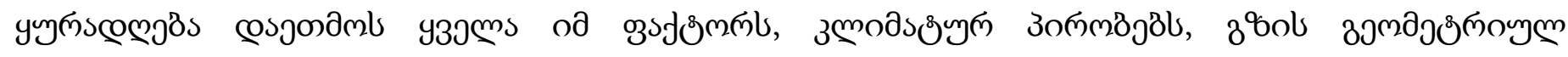

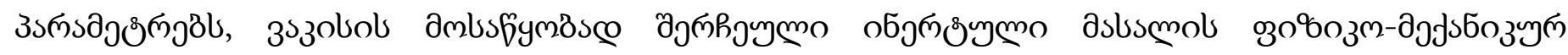

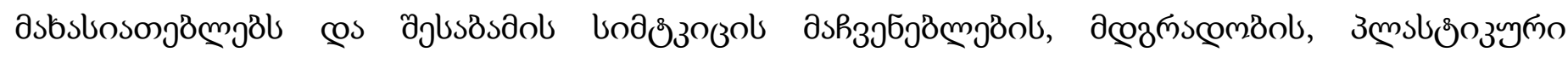

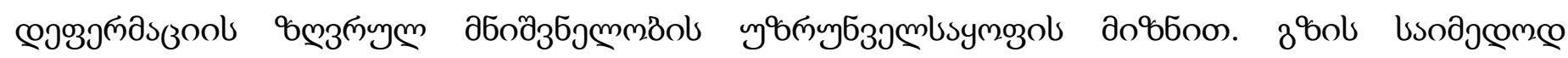

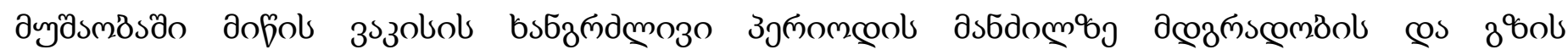

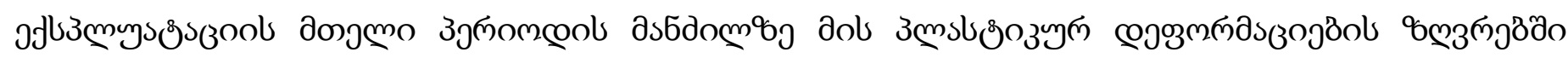

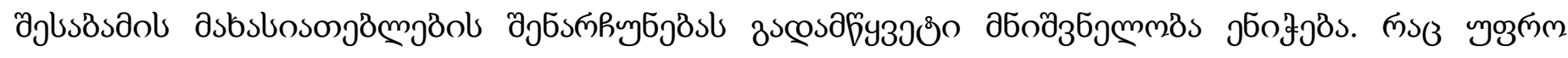

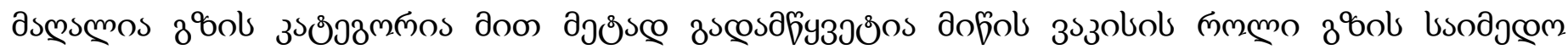

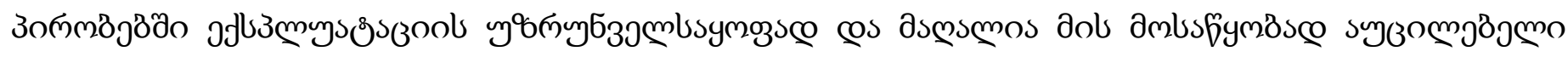

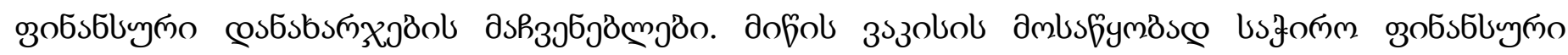

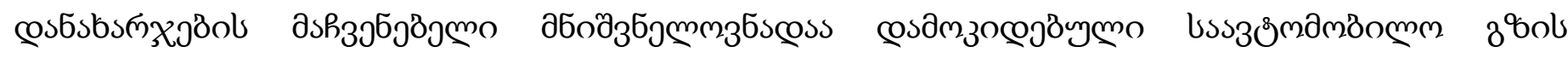

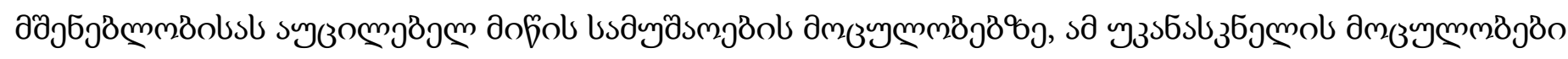

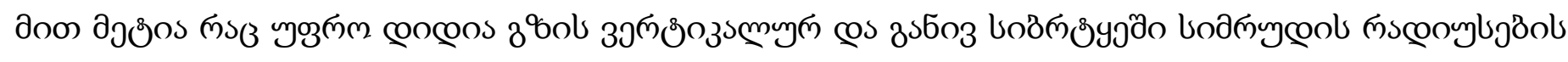

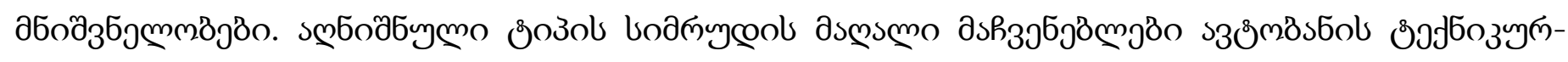

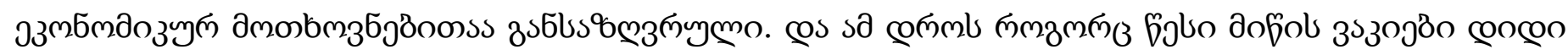

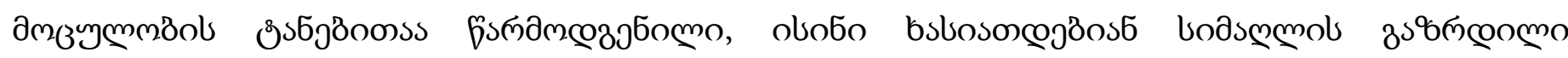




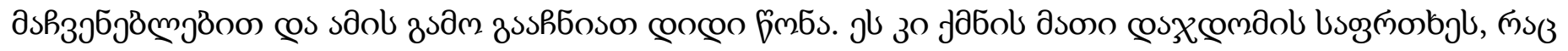

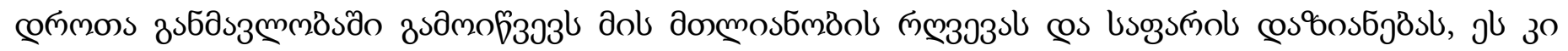

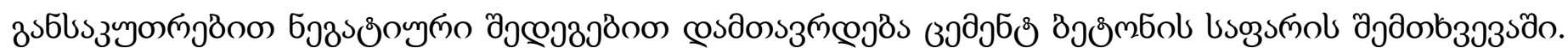

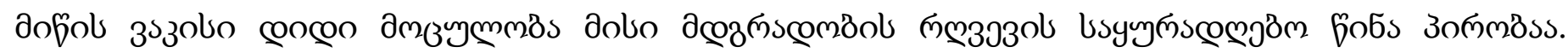

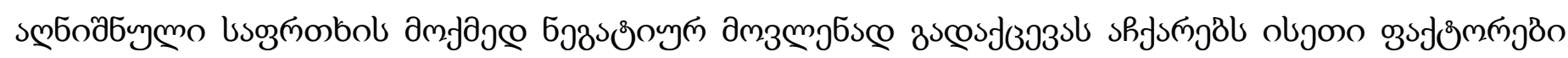
пмдмповоз;

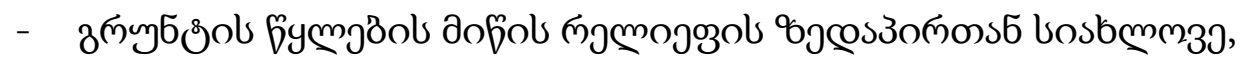

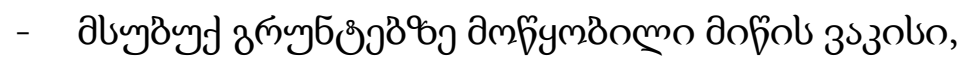

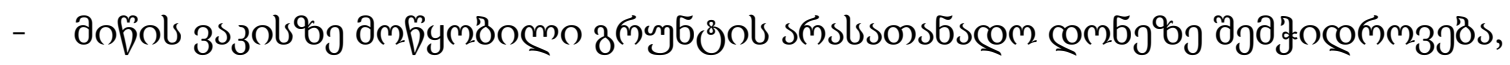

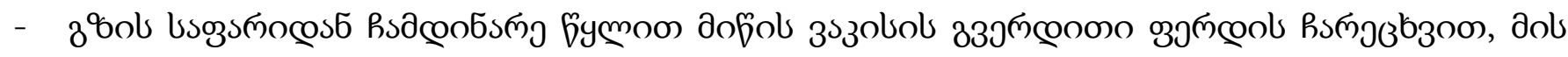

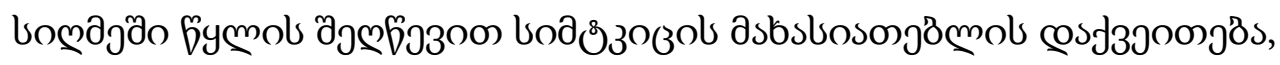

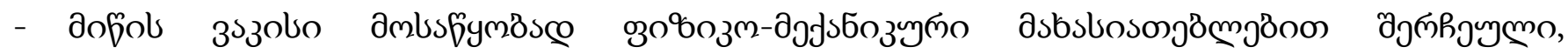

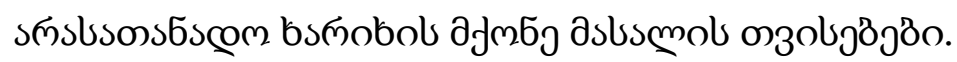

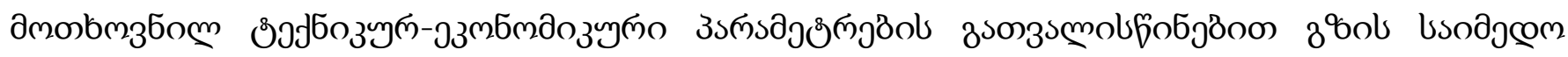

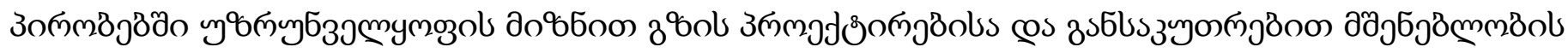

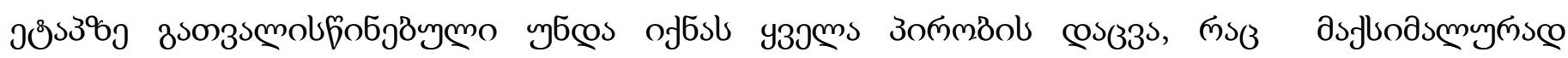

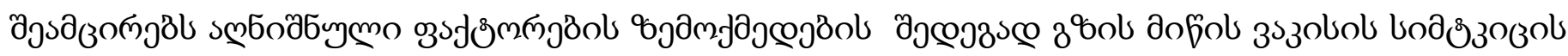

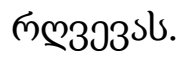

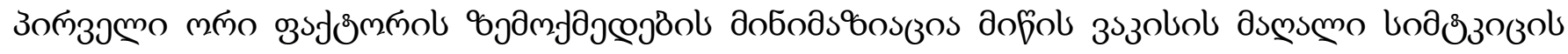

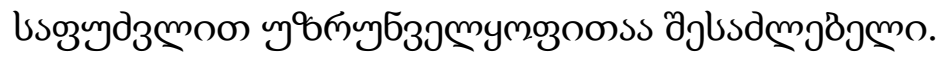

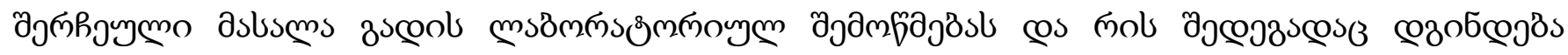

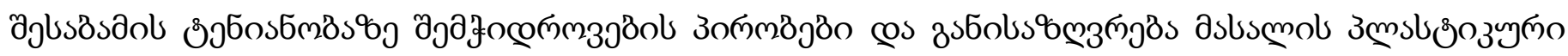

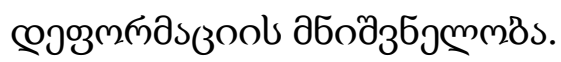

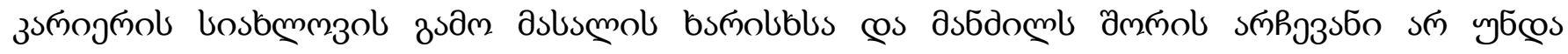

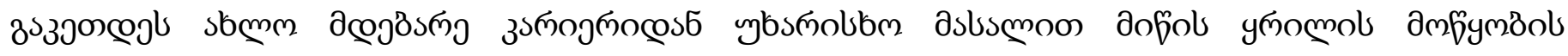

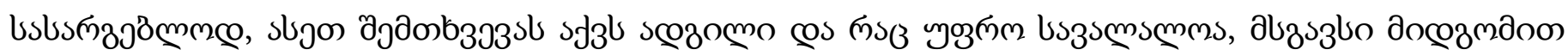

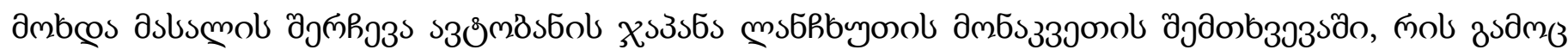

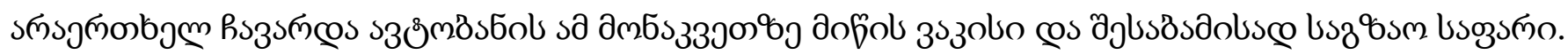




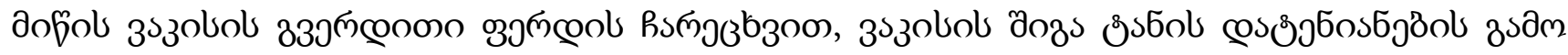

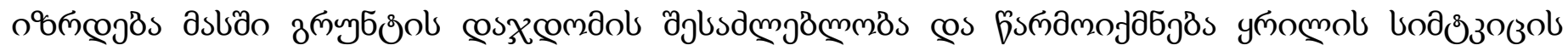

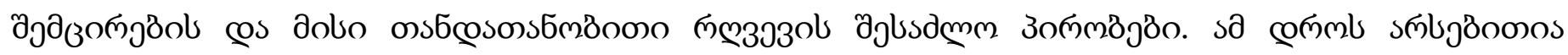

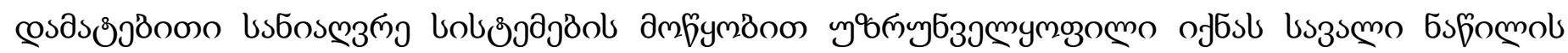

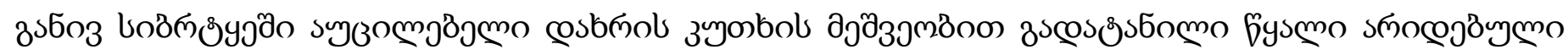

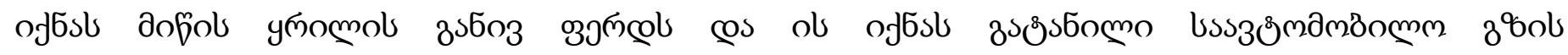

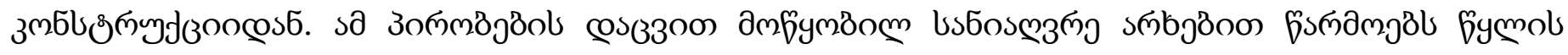

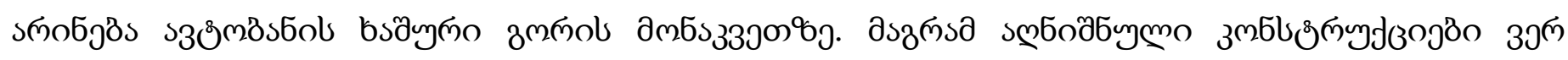

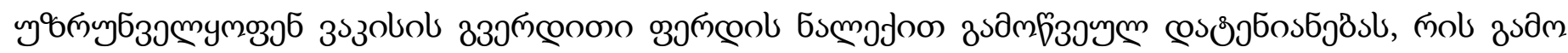

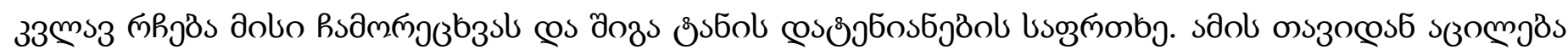

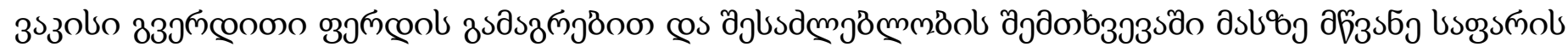

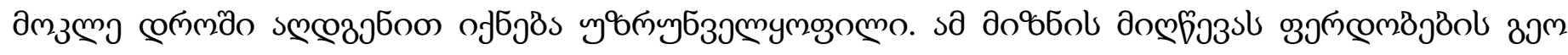

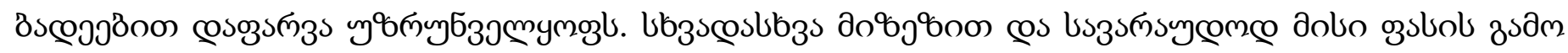

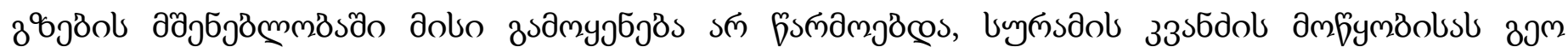

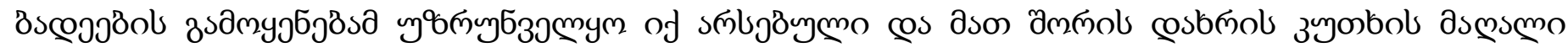

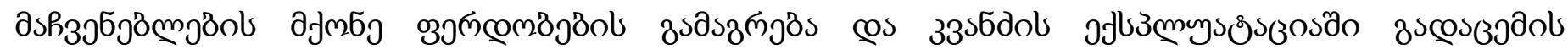

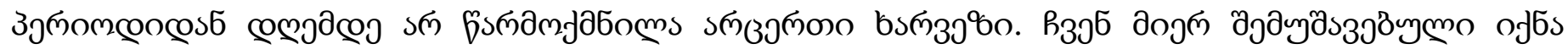

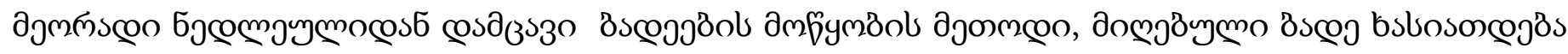

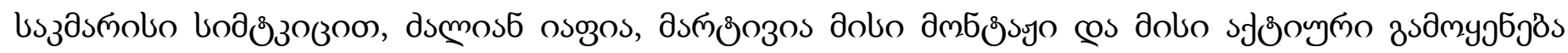

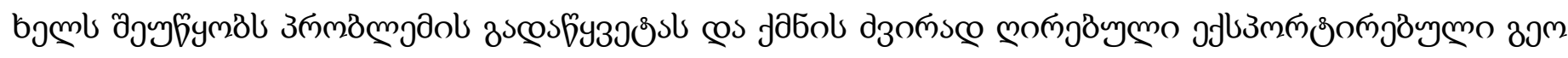

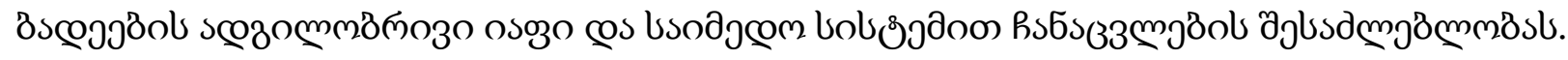




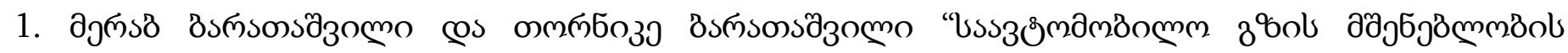

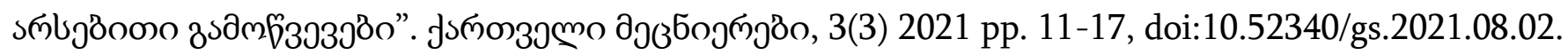

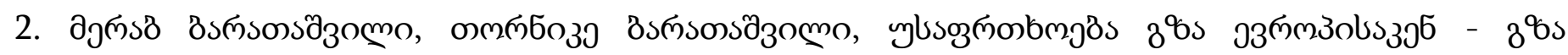

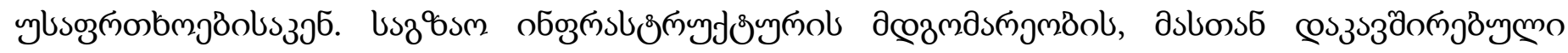

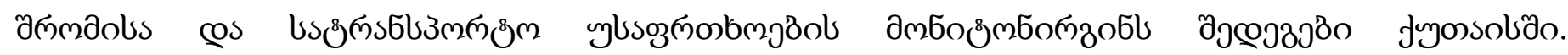

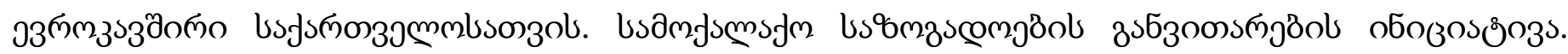

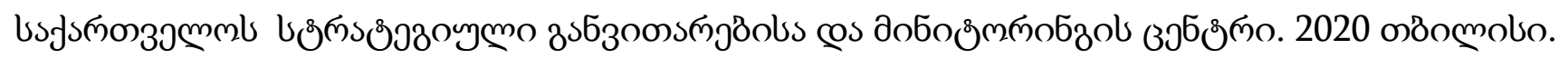

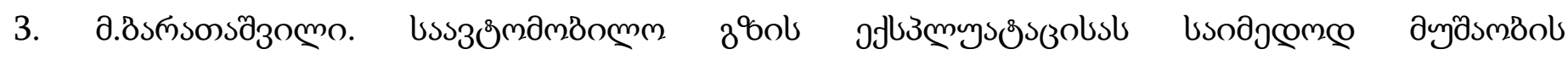

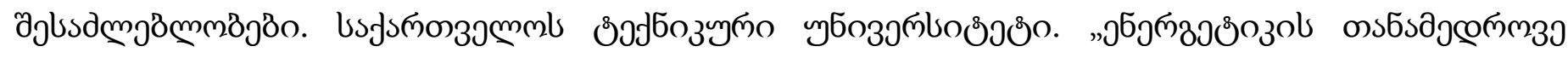

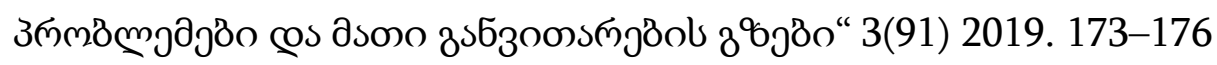

\title{
Opportunities to increase road reliability
}

\author{
Merab Baratashvili; Tornike Baratashvili
}

Akaki Tsereteli State University

\begin{abstract}
The article discusses all the factors that should be paid attention to at the pre-design stage of design, the correct collection of this information allows you to effectively manage the design work. With proper coating, it will withstand many adverse conditions. Important factors are listed that sharply reduce the reliability of the road section, jeopardizing its stability and strength, and ways to eliminate the threats posed by these factors are presented.
\end{abstract}

Search Keywords: Road, Vaccine, Hardness, Plastic Deformation, Geo-Mesh, Moisture, Projection, Deformation, Inert Material. Highway. 